\title{
MIGRAÇÕES INTERNACIONAIS os blocos regionais e a mobilidade mundial de mão-de-obra
}

Arnaldo Francisco Cardoso

\begin{abstract}
Resumo: As migrações internacionais nos últimos anos, ganhou nova dinâmica expressou-se, devido à formação de blocos regionais e as transformações tecnológicas por que passam a produção e comercialização de bens e serviços com a globalização, configurando novo estágio da mobilidade mundial de mão-de-obra. Palavras-chave: mobilidade mundial; migrações internacionais; consenso social.
\end{abstract}

Abstract: In recent years, international migration trends have changed in nature, most notably due to the formation of regional blocks and the technological transformations affecting the production and sale of goods and services, defining a new era in the worldwide mobility of labor.

Key words: worldwide mobility; international migration; social consensus.

A formação de blocos regionais como Nafta, União Européia e Mercosul, trouxe consigo a atualização de problemas historicamente associados a fluxos migratórios que ao longo do século XX, mesmo que episodicamente estiveram presentes nas agendas políticas de um número significativo de países.

Nos últimos anos, o debate em torno de problemas atinentes a imigração ganhou fóruns próprios, como a Conferência Internacional sobre População e Desenvolvimento realizada na cidade do Cairo em 1994, por iniciativa do Fundo de População das Nações Unidas, e o Encontro Europeu da Organização Internacional do Trabalho organizado na sede de Genebra da OIT, entre 12 e 15 de dezembro de 2000. Nestes fóruns, as questões tratadas encontram suas raízes em problemas clássicos que envolvem migrações internacionais; entretanto, elas vêm escapando às formas tradicionais de concepção e condução de ações dos governos nessa área.

Têm-se que, a cada momento, as questões lançadas pela dinâmica das migrações internacionais ganham novos contornos e dimensões, avançando para além das esferas mais diretamente e imediatamente implicadas pelas transformações econômicas e políticas que agitaram o mundo desde o final dos anos 80 .
Aqui, ressalta-se o notável aumento das migrações inter e intrafronteiras registrado nos últimos anos, ${ }^{1}$ com mudanças no perfil do imigrante, ainda que a centralidade do trabalho continue predominando.

Neste particular, registra-se o crescimento da oferta de empregos no setor das TIC (Tecnologias da Informação e da Comunicação) que tem desencadeado novas situações que transbordam para o debate político, lançando questões quanto aos meios de consecução de projetos de desenvolvimento concebidos pelos governos de diferentes nações.

Sob a força das circunstâncias - após os atentados terroristas que atingiram os Estados Unidos no último 11 de setembro -, um aspecto referente às migrações internacionais ganhou destaque na discussão e encaminhamento de ações nos Estados Unidos e em diferentes partes do mundo; trata-se do reforço da segurança de fronteiras, que mesmo antes do referido atentado terrorista aos Estados Unidos, já suscitava agudos debates em parlamentos nacionais e fóruns internacionais - ainda que, percebido até então, por uma óptica com predominância orientada pelo cálculo econômico.

Concomitante a esses, o debate no campo dos direitos humanos, nos últimos anos, veio repondo questões sobre 
diversidade étnica, proteção de minorias e o crescimento do tráfico de pessoas pelo mundo; referente ao tráfico, fora objeto de declarações públicas do Secretário de Estado dos Estados Unidos, Colin Powell, por ocasião da conclusão e divulgação do primeiro Relatório Anual de Tráfico de Pessoas do Departamento de Estado dos Estados Unidos, em julho de 2001. Em matéria publicada pelo jornal The New York Times (13/07/2001) tem-se que: "A CIA estima que pelo menos 700 mil pessoas são traficadas entre países a cada ano; esta estimativa também mostrou que entre 45 e 50 mil destas pessoas são traficadas para os Estados Unidos"; estes dados geraram a seguinte declaração de Colin Powell: "É incompreensível que o tráfico de seres humanos esteja ocorrendo no século 21 , algo incompreensível mas real, muito real." (O futuro próximo se lhe apresentaria, causando ainda maior estupefação.).

O recrudescimento de conflitos raciais em diferentes países, desde muito, vem toldando os cenários mais otimistas traçados para o século recém-inaugurado. Quanto ao papel que as migrações internacionais vêm ocupando no contexto da globalização, faz-se forçoso lembrar, períodos como aquele entre os anos de 1960 e a eclosão da crise do petróleo de 1973, quando países como Inglaterra, Alemanha e em menor escala a França, atendendo a demanda de um momento de crescimento econômico, promoveram grandes ações visando a entrada de mão-de-obra estrangeira em seus territórios. Hoje vivem nesses países, as segundas e terceiras gerações desses imigrantes dos anos 60 , o que suscita situações em torno de questões ainda mal resolvidas, tanto pelos governos quanto pelas sociedades que os atraíram e hoje os repelem. É dessa época - quando a Alemanha "convidou" milhares de imigrantes turcos para trabalhar em solo alemão - a representativa frase atribuída ao escritor Max Frisch: "Importamos mão-de-obra, recebemos seres humanos". A experiência vem retificando-a.

Até pouco antes do último 11 de setembro, a concomitância de propostas de anistia à imigrantes ilegais (chamados "indocumentados"), reforço dos investimentos em segurança de fronteiras e carência de mão-de-obra (qualificada e não-qualificada) configurando-se em ameaça a estabilidade econômica de diferentes países, apontava para um descompasso ou desarticulação entre diferentes iniciativas, causando aturdimento e minando tentativas mais ousadas de um entendimento concatenado da situação das migrações internacionais, estimulando, assim, análises fragmentadas e um pernicioso relativismo.

Numa perspectiva econômica, tem-se que, uma das faces da globalização é a dinamização da mobilidade mun- dial de mão-de-obra, destinando alguns países a ser terra de imigração e lançando-os numa concorrência internacional por mão-de-obra qualificada.

Ao mesmo tempo, proliferam deslocamentos clandestinos de pessoas que, transpondo fronteiras nacionais, abrem espaços mediante precárias práticas e ações conduzidas por atores imanentemente marginais, que operam via "redes" interagindo com os que buscam resistir ao fatalismo da exclusão de um mundo próspero ao qual não estão convidados a participar. As transformações em curso no mundo vieram redesenhando-o, criando uma nova cartografia pautada por uma geografia econômica, cujos contrastes fazem-se mais nítidos.

Quando fronteiras nacionais flexibilizam-se em favor de blocos regionais, novos muros projetam-se alhures. Os 15 quilômetros de mar que separam o norte do Marrocos da Espanha passa a ser o equivalente europeu do rio Grande, que se constitui em obstáculo aos imigrantes ilegais mexicanos em alcançar o solo norte-americano. Os 686 quilômetros de fronteira entre a pobre Romênia e a Moldávia (ex-integrante da URSS) adquire status de fronteira oriental da União Européia, bem como a Turquia passa a ser percebida por muitos como um portal para a zona de prosperidade da UE.

Em seu interior, espreitam-os as insurgências e reminiscências de caráter identitário, enquanto nas vizinhanças desses blocos, agudizam-se ressentimentos históricos e conflitos que, ao avolumarem-se, transbordam de seu âmbito doméstico, adquirindo potencial instabilizador de contextos regionais e até mesmo da própria ordem mundial.

Os problemas concernentes às diferentes situações de imigração no mundo contemporâneo apontam para a necessidade de mudanças na concepção e condução de políticas governamentais e das leis que tratam da imigração e do estrangeiro, passando por aspectos jurídicos (desde a entrada do imigrante em solo estrangeiro, manutenção da legalidade de sua condição de estrangeiro no país, passando pela situação de estrangeiros legais condenados por diferentes crimes cometidos no país anfitrião), ${ }^{2}$ até questões em que o papel atribuído ao imigrante no contexto econômico-político do país que o recebe, reflita as condições de integração social deste no país anfitrião, passando por uma necessária reflexão de governos e sociedades (destaque aos países conhecidos como "países-destino de imigração") quanto ao tipo de consenso social almejado pela sociedade anfitriã e quanto à disposição do estrangeiro que nela ingressa. ${ }^{3}$ 
Quanto as migrações internacionais, ainda é reduzido o número de pesquisas e publicações voltadas às novas dimensões dos fluxos migratórios e os desafios que se nos colocam. Importantes iniciativas têm ganho impulso nos últimos anos, e a própria imprensa internacional vem aos poucos ampliando os espaços destinados às temáticas da imigração.

A compreensão do fenômeno das migrações internacionais em nossos dias, passa necessariamente, por um mapeamento dos atuais países-destino de imigração - em sua condição relativa aos blocos regionais que integram -, e das principais situações de migração.

De semelhante exercício, pode-se extrair elementos que se constituam em ferramenta para uma crítica às formas tradicionais de condução e implementação de políticas migratórias por parte dos governos nacionais, inquirindo - quando menos - quanto à sua racionalidade e ao seu alcance, diante de erros grosseiros do passado, re-orientar as ações que implicam aumento do intercâmbio entre povos, culturas e civilizações, de forma a salientar os riscos contidos em um soterramento dessas pelo dínamo da economia de nações que se encontram no topo do capitalismo avançado.

\section{OS ESTADOS UNIDOS - PRINCIPAL PAÍS- DESTINO DAS MIGRAÇÕES INTERNACIONAIS}

\section{O Setor de Alta Tecnologia nos Estados Unidos e os Imigrantes Superqualificados}

A demanda por mão-de-obra qualificada - destacadamente no setor das tecnologias de informação e comunicação (TIC) - nos países de economia avançada, tem crescido a taxas médias de $8 \%$ ao ano, como indicou relatório divulgado em dezembro de 2000, pela OIT.

No relatório citado, projeta-se para o ano de 2003 um número de 12,3 milhões de empregos no setor das TIC contra 9 milhões computados no ano de 1998. Esses números, mais que euforia, causam preocupação, pois prognosticam uma agravante carência de mão-de-obra especializada no mundo.

Os Estados Unidos e os principais países membros da União Européia vêm implementando medidas para o enfrentamento do problema, que se revela mais crítico no caso da Europa. As duas formas clássicas de lidar com a escassez de mão-de-obra têm alternado entre: formação e imigração.

A opção de um governo pela imigração como forma de enfrentamento da falta de mão-de-obra, costuma sustentar-se numa avaliação pragmática de eficiência e rapidez no trato do problema, desconsiderando outras dimensões da questão.
Para o país cedente de mão-de-obra qualificada, a perda é evidente, uma vez que se opera uma drenagem de trabalho qualificado. (A Bulgária veio a ser um caso notório de perda de capital humano, com profissionais formados pelas instituições estatais de ensino "exportados" para países europeus de economia mais avançada, ao longo da década de 90).

O Estado da Califórnia, na costa oeste dos Estados Unidos, abriga as principais empresas de tecnologia da informação e comunicação dos Estados Unidos, e do mundo. No ano de 2000 o PIB dessa região atingiu a cifra de US\$ 1,33 trilhão que, se projetado no ranking dos PIBs das principais nações do mundo, ocuparia uma quinta posição. A Califórnia possui uma população de 33,9 milhões de habitantes, e a renda anual por morador é de US\$ 39,2 mil, conforme divulgações parciais do censo norteamericano de 2000.

Esta região tem-se tornado importante pólo de atração de especialistas e "jovens talentos" e tem dinamizado o mercado de mão-de-obra superqualificada, causando inquietação nas principais economias do mundo globalizado.

O tipo de visto concedido aos trabalhadores estrangeiros superqualificados que chegam aos Estados Unidos, é o visto denominado $\mathrm{H}-1 \mathrm{~B}$, concedido para um emprego específico, sem previsão de promoções ou mudanças que impliquem uma ascensão na carreira - caso ocorra, a tramitação burocrática tem de ser reiniciada. Esses vistos tem duração de 6 anos que, uma vez expirado, o Serviço de Imigração deve avaliar a concessão ou não do green card.

Os Estados Unidos vêm admitindo, anualmente, cerca de 195 mil novos trabalhadores H-1B. Cerca de 57\% de todos os H-1B estão sendo concedidos para imigrantes provenientes da Índia e da China. Um controle de cotas de green cards deve ser revisto pelo Congresso, em que propõe-se que as cotas não aproveitadas por pequenos países possam ser transferidas para países maiores e com maior demanda por vistos.

Diversas questões decorrentes das relações entre esses profissionais estrangeiros, seus empregadores e os sindicatos norte-americanos, têm feito com que três agências de Estado - Departamento do Trabalho, Departamento de Estado e o Serviço de Imigração e Naturalização - envolvidas na administração do programa de recepção desses imigrantes, vejam-se embrenhados num cipoal de regras que a cada dia tem tornado mais difícil a fiscalização dessas complexas relações. 
Atualmente, existem nos Estados Unidos, 420 mil indivíduos com vistos $\mathrm{H}-1 \mathrm{~B}$ prestes a expirar, aguardando ser expedidos seus green cards - documento este que lhes dá o direito de residir e trabalhar naquele país. Entre esses imigrantes, os que não receberem uma renovação de visto de um ano, podem se ver forçados a deixar o país. Se um trabalhador H-1B ficar desempregado por mais de 10 dias, ele está "fora do status" e pode receber a ordem de deixar o país imediatamente.

São contratantes de H-1Bs, empresas da área de tecnologia como a Microsoft, Intel, e grandes consultorias como a Goldman Sachs, Merril Lynch, Deloitte Consulting e Ernst \& Young.

O demorado processo de obtenção do green card faz com que os trabalhadores H-1B fiquem vulneráveis ao abuso e à exploração, além do grau de ansiedade que acomete esses profissionais, fazendo com que muitos definam sua situação como "vivendo num limbo" sem saber que país devem chamar de lar. Sabem que os Estados Unidos vivem um momento em que precisam da mão-deobra de estrangeiros, que entram no país por meio de processos legais, mas sentem-se marginalizados em relação à sociedade norte-americana.

A esses empregados também é vedada a aspiração estimulada entre os norte-americanos - de realizarem seu "espírito empreendedor" tornando-se um empresário, pois para os portadores do visto H-1B é condição para sua permanência nos Estados Unidos o vínculo empregatício que expressa a "tutela" do empregador sobre o empregado.

A liberdade outrora sedutora, revela-se então dotada de menos brilho, questão que fora bem sintetizada nos seguintes termos: "os Estados Unidos, como país de destino das migrações internacionais, têm como um dos ingredientes intrínsecos a sua auto-representação como a terra das oportunidades, representação essa amplamente assentada nos pressupostos da competição individual. $\mathrm{O}$ suposto que está por trás da competição individual, por sua vez, é o da igualdade de oportunidades" (Salles, 1995).

Os trabalhadores sindicalizados - minoria no setor de tecnologias -, e os profissionais norte-americanos do setor reconhecem no programa de recepção de imigrantes com vistos H-1B um ardil para o aumento de lucros mantendo os salários reprimidos - e os sindicatos apontam também para a facilidade de dispensar esses trabalhadores estrangeiros quando não forem mais necessários.

É pouco conhecido o lado escuro das empresas propulsoras da Nova Economia, localizadas no Vale do Silício: trabalhadores pouco qualificados, contratados como temporários, trabalhando longas jornadas, montando e embalando impressoras e outros equipamentos é uma parte da realidade, desconhecida por aqueles que acompanham os índices da bolsa Nasdaq.

Das batalhas encampadas pelos sindicatos do setor, resultaram apenas a elevação das despesas para os empresários na contratação dos trabalhadores com vistos $\mathrm{H}-1 \mathrm{~B}$, e um aumento colossal da burocracia que já gerou uma nova modalidade de serviços oferecidos por escritórios em Wall Street: a assessoria em contratação de profissionais H1-B.

Um dos talentosos detentores de visto H1-B foi o jovem finlandês de 31 anos, Linus Torvalds - que obteve recentemente seu green card - criador do sistema operacional Linux. O Linux - software livre - tem sido uma poderosa arma do governo norte-americano contra a ameaça de monopólio representada pelo Windows - software proprietário - da poderosa Microsoft. Em disputa judicial recente envolvendo o governo dos Estados Unidos e a Microsoft, o presidente Bush ameaçou substituir todos os softwares da administração pública norte-americana pelo Linux, usando assim o poder de compra do governo para estimular o desenvolvimento da concorrência no setor.

Sobre o perfil desses trabalhadores superqualificados são, em sua maioria, jovens, com títulos de mestrado, provenientes das melhores universidades de seus países, atraídos por salários superiores ao que ganhariam em sua terra natal.

Países como o Canadá vêm agilizando seus processos de recepção de mão-de-obra qualificada, facilitando a aquisição de vistos de residência permanente para esses trabalhadores superqualificados. A Austrália e a Nova Zelândia vêm adotando políticas similares.

O Serviço de Imigração e Naturalização dos Estados Unidos, atentos à competição e à percepção de como o aumento do número dos trabalhadores do setor das TIC tornou-se um elemento de política nacional para muitos países, veio orientando suas ações buscando garantir a esse país posição de destaque. No presente momento, não se tem ainda condições de avaliar os impactos do último 11 de setembro sobre estas ações do INS dos Estados Unidos, nem tampouco, sobre outros países dependentes de mão-de-obra superqualificada estrangeira.

\section{Mexicanos nos Estados Unidos. Braços ou Cidadãos?}

A fronteira dos Estados Unidos com o México constitui-se em permanente fonte de preocupação na pauta de imigração para o governo norte-americano. Desde a criação do Nafta, ampliou-se o intercâmbio entre mexicanos e 
americanos; um dos notáveis reflexos foi o enriquecimento do norte do México, sem que isso se traduzisse em estímulo à permanência do mexicano em solo nacional. Assim, concomitante à liberalização da circulação de bens, incrementou-se as restrições ao trânsito de pessoas entre os dois países. ${ }^{4}$

$\mathrm{O}$ recurso de reforçar a vigilância sobre as fronteiras ainda é o mais adotado pelos governos, embora seus resultados estejam sempre aquém do esperado. Os Estados Unidos, por exemplo, gastaram em 2000 cerca de US\$ 2 bilhões em sua fronteira com o México, reforçando o contingente policial e as tecnologias empregadas. No entanto, o número de mexicanos que trabalham ilegalmente nos Estados Unidos em 2001 atingiu cifras recordes.

À medida que se reforçam os mecanismos de controle das fronteiras, formam-se novas "redes", desafiando os obstáculos legais. Ganha destaque a ação dos "coyotes" (homens que se especializam em burlar os controles da fronteira e facilitar a entrada de imigrantes ilegais no país-destino). No ano de 2000 , registrou-se a morte de 491 mexicanos no espaço fronteiriço entre os Estados Unidos e o México. Cada imigrante ilegal paga - antecipado - aos "coyotes" algo em torno de US $\$ 2.500$ pelos seus "serviços".

Estatísticas recentes apontam que a população de origem mexicana que vive nos Estados Unidos é de 20,6 milhões de pessoas dos quais até 5 milhões estão ilegalmente. Por mais paradoxal que possa parecer, empresários americanos têm cruzado a fronteira em busca de empregados. Diante de prognósticos alarmistas de uma "mexicanização" dos Estados Unidos, o pragmatismo parece estar-se sobrepondo ao preconceito. Sobre o papel que as empresas exercem nesse cenário, encontramos assim formulado por Ianni (1996:4): "Jogando com as convergências e os antagonismos entre nacionalismo, regionalismo e globalismo, encontram-se as empresas, corporações e conglomerados transnacionais. Tecem a globalização desde cima, em conformidade com a dinâmica dos interesses que expressam ou simbolizam. Desenham as mais diversas cartografias do mundo, planejadas segundo as suas políticas de produção e comercialização, preservação e conquista de mercados, indução de decisões governamentais em âmbito nacional, regional e mundial."

A mão-de-obra mexicana faz-se presente em diferentes setores da economia dos Estados Unidos, da agricultura à construção civil, passando pelo processamento de alimentos e até mesmo ocupando cargos em empresas de alta tecnologia.
As remessas de dinheiro para o país natal, de mexicanos que trabalham nos Estados Unidos, somou no primeiro trimestre de 2001 a cifra de US\$ 2,1 bilhões, sendo importantíssima fonte de renda do México.

No fim de junho de 2001, Estados Unidos e México apresentaram o Plano de Ação para a Cooperação sobre Segurança Fronteiriça, segundo o qual, cabe às autoridades norte-americanas revisar as operações de controle na fronteira e às autoridades mexicanas, demover a população da idéia de cruzá-la.

O presidente Vicente Fox comprometeu-se com as autoridades norte-americanas em aumentar o controle sobre a sua fronteira meridional, visando conter a entrada de migrantes através das fronteiras com Guatemala e Belize, que serve de porta de entrada de latino-americanos e outros, das mais variadas procedências, passando pelo México e que tem como país-destino os Estados Unidos. Desse fluxo resultou a deportação feita pelo México, de mais de 150 mil estrangeiros no ano de 2000. Estima-se que um em cada quatro ilegais são detidos.

O senador Phil Gramm (republicano, Estado do Texas) é o autor de um plano para receber mexicanos convidados para trabalhar. Segundo sua proposta, o governo americano estipularia uma cota para a entrada de mexicanos em busca de trabalho. Depois de selecionados por um mecanismo binacional, eles receberiam um visto especial de "guest worker" - válido por um ano e renovável por até duas vezes -, após esse período, o mexicano seria "desconvidado" e mandado de volta.

Phil Gramm é opositor da proposta de anistia de $3 \mathrm{mi}-$ lhões de mexicanos ilegais, desenvolvida pela equipe do Secretário de Estado Colin Powell e do Procurador Geral da República John Ashcroft, por considerá-la "uma recompensa à infratores da lei" e em matéria publicada no jornal The New York Times (15/07/2001) afirmou que qualquer programa de anistia só será aprovado sobre o seu "frio e inerte cadáver político". Ressalte-se que essas posições só vieram por reforçar-se após o último 11 de setembro; o diretor do Serviço de Imigração e Naturalização (INS) dos Estados Unidos, James Ziglar, sofre cada vez mais pressão dos grupos conservadores do Congresso, a fim de endurecer a política de imigração.

\section{Latinização dos Estados Unidos ou Capacidade de Assimilação?}

A divulgação parcial do Censo 2000 dos Estados Unidos, em meados de 2001, alarmou parte da população nor- 
te-americana, pois revelou que a presença hispânica nos Estados Unidos cresceu 57,9\% na última década - de 22,4 milhões em 1990 para 35,3 milhões em 2000.

O Departamento de Educação dos Estados Unidos estima que em 2001 o número de jovens matriculados no segundo grau no país girou em torno de 13,3 milhões, dos quais um quarto estudaram espanhol.

A questão do estudo de idiomas nos Estados Unidos fez com que se realizasse uma audiência no Senado americano no final do ano de 2000, contando com a presença de professores de idiomas à agentes da CIA, onde expôs-se aos membros do Comitê de Assuntos Governamentais que "os norte-americanos monoglotas estão mal preparados para lidar com diversos assuntos, de guerra ao comércio e espionagem internacional" (USA Today, 09/05/2001).

As escolas particulares, que ensinam o idioma espanhol, têm proliferado nos Estados Unidos. Sam Slick, fundador da Command Spanish, a maior empresa dos Estados Unidos voltada ao ensino do idioma espanhol nas empresas, declarou à mesma edição já citada do jornal USA Today: "Não há nada de estrangeiro em relação ao espanhol, hoje em dia. Trata-se do segundo idioma dos Estados Unidos". A Command Spanish fornece materiais para diversas faculdades, empresas e até mesmo orgãos oficiais do Estado como, por exemplo, o Centro de Justiça Criminal do Alabama.

O presidente dos Estados Unidos George W. Bush demonstrou assimilação da realidade quando nos primeiros dias de maio de 2001, fez seu primeiro discurso de rádio em inglês e espanhol.

Na segunda semana de julho de 2001, numa cerimônia em Ellis Island, o presidente Bush declarou: "Os Estados Unidos sempre foram uma nação hospitaleira [...] Nós recebemos de braços abertos não-somente os imigrantes como também seus talentos, seus valores e seus estilos de vida" (The New York Times, 15/07/2001).

Se o que orienta as ações do presidente Bush, no tocante à imigração - em especial de latinos -, são as contingências de uma conjuntura macroeconômica, uma percepção do papel dos Estados Unidos no continente americano, ou um mero pragmatismo eleitoral, é algo que o conjunto de ações, ao longo de seu governo, poderá revelar. No pleito de 2000, Bush teve um terço dos votos da comunidade latina; ampliar essa margem pode ser-lhe decisivo para uma futura tentativa de reeleição. É consensual a avaliação de que nenhum candidato à presidência dos Estados Unidos pode desprezar a força que o eleitorado de origem hispânica representa num pleito america- no. No entanto, coloca-se ainda como incógnita a amplitude dos reflexos do atentado terrorista sofrido pelos Estados Unidos, no ânimo dos norte-americanos diante de entrangeiros de modo geral.

A sedução do mero cálculo eleitoral, quanto aos votos de origem latina, pode tirar de foco uma gama de problemas que, potencializados pelo fermentar do tempo, venha a adquirir contornos críticos.

Abordando aspectos da delicada questão das políticas migratórias, o professor Lélio Mármora (1996:55-6), da Universidade de Buenos Aires, aponta que: "As políticas migratórias são parte das políticas públicas e, portanto, corresponde ao governo de cada Estado tomar as decisões básicas para defini-las e poder aplicá-las. A específica e determinada percepção que o Estado tenha das migrações será o fundamento para a elaboração dessas políticas e seu conseqüente plano de ação.[...] Mas o problema se coloca ao se tentar falar do Estado como um bloco em sua percepção e ação política frente a esse fenômeno."

Educação nos Estados Unidos: A Carência de Professores Norte-Americanos - No tocante à imigração e a área da educação nos Estados Unidos, merece nota o crescente aumento do número de contratações de professores estrangeiros para os colégios norte-americanos, em face da carência de professores nativos.

Em matéria publicada no jornal The New York Times (23/05/2001), destaca-se que: "Em Palm Beach, Flórida, representantes das escolas estão planejando uma viagem coletiva para as Filipinas no final deste mês. Em Nova York, o conselho municipal de educação organizou e divulgou amplamente uma procura por professores austríacos. O sistema educacional de Chicago contratou neste ano 71 professores vindos de 28 países, entre eles China, França e Hungria.

Representantes do município de Houston foram a Moscou e voltaram com onze professores. Educadores de Fulton, Ga., já realizaram viagens para a África do Sul, Austrália e Nova Zelândia. Uma viagem para a Jamaica foi agendada. [...] Em 2000 foram recrutados 1.300 professores vindos de 35 países, e encaminhados para escolas de oito estados americanos. No ano letivo de 2001/02 estima-se que chegarão mais 1.800 ou 2.000 professores."

Um dos fatores, em geral, apontados para a explicação da baixíssima oferta de profissionais norte-americanos nesta área, é em relação a pouca atratividade dos salários pagos aos professores, considerando as exigências de uma carreira na área educacional; e isso tem levado à crescen- 
te demanda por professores estrangeiros, para manutenção dos quadros docentes nos Estados Unidos.

Ainda que o fenômeno da imigração seja quase indissociável da própria história dos Estados Unidos - destacadamente durante o século XX -, o que se pode observar no presente, quanto a relação: trabalho e mão-de-obra estrangeira nos Estados Unidos, é a potencialidade desta, em projetar questões sobre a prática da democracia vivida nos Estados Unidos, sobretudo no tocante aos valores que animam seus diferentes cidadãos, o que nos leva a considerar supostos riscos à manutenção de um mínimo consenso social, tão difícil e ao mesmo tempo necessário, em sociedades com elevado grau de complexidade e elevada diferenciação entre seus integrantes.

Outro aspecto significativo, da relação migrações internacionais e ensino nos Estados Unidos, diz respeito ao contingente de estudantes estrangeiros matriculados nas universidades norte-americanas. Dados do ano acadêmico 1999-2000 apontam que 514.723 estudaram nos Estados Unidos, trazendo para o país algo em torno de US\$ 12,3 bilhões. Especialistas em ensino apontam que as universidades norte-americanas são enormemente fortalecidas pela diversidade existente em seus campi, constituindo-se assim em elemento indispensável à manutenção da excelência de diversas instituições. Os países que mais remetem estudantes aos Estados Unidos são, respectivamente, China, Japão e Índia.

Logo após os acontecimentos do último 11 de setembro, importantes jornais deram destaque ao fato de entre os suspeitos seqüestradores dos aviões lançados contra as torres do W.T.C. e do Pentágono encontravam-se: Hani Hanjour, que entrou no país alegando intenções de estudar inglês numa universidade em San Francisco, mas nunca foi às aulas; e Walled Alsheri, formou-se em ciência aeronáutica, em 1997, na Universidade Aeronáutica EmbryRiddle, na Flórida.

É evidente que esses casos sequer podem representar um número em estatísticas, mas para a opinião pública, a exceção pode servir à regra.

\section{UNIÃO EUROPÉIA E OS DIFERENTES CONTEXTOS DE IMIGRAÇÃO ENTRE SEUS PAÍSES MEMBROS}

\section{Desafios da Imigração na Alemanha}

A exemplo de outros países de economia avançada, a Alemanha vem-se lançando na concorrência internacio- nal por mão-de-obra qualificada, entretanto, enfrenta dificuldades nessa seara.

Desde o balanço realizado em março/2001, após sete meses da entrada em vigor (agosto/2000) do "plano de urgência" visando recrutar 10 mil especialistas estrangeiros em informática (a meta inicial era de 30 mil) - com objetivo de combater a carência de mão-de-obra no campo das tecnologias de informação e comunicação (TIC) -, acirrou-se o debate na Alemanha em torno da questão da imigração. $\mathrm{O}$ balanço da operação apontou que apenas 5.533 pessoas haviam-se beneficiado dos "vistos de trabalho" oferecidos pelo programa do governo.

Enquanto a Federação Alemã da Indústria (BDA) acreditava que a meta de 10 mil contratações poderia vir a ser atingida em poucos meses, para muitos analistas, o resultado dos sete meses de vigência do programa serviu como indicador de que a economia alemã mostra-se menos atraente que suas concorrentes britânica e americana no mercado internacional do trabalho.

Os "vistos de trabalho" alemães têm o prazo máximo de validade de cinco anos, mas mudanças vêm sendo analisadas; uma delas é a ampliação para seis anos do "visto de trabalho" e redução dos atuais oito anos para seis anos de residência - de modo a coincidirem os prazos - como requisito para a concessão do passaporte alemão. Os trâmites para a concessão desses vistos vêm sendo amplamente simplificados, podendo ser expedidos num prazo de uma semana.

A Bundesanstalt für Arbeit - agência do governo alemão que lida com assuntos referentes ao emprego - vem enfrentando duras críticas perante a incômoda cifra de 4 milhões de desempregados na Alemanha e as medidas de facilitação da contratação de estrangeiros. Note-se, no entanto, que apenas assalariados altamente qualificados são contemplados com as facilidades para esse tipo de "visto de trabalho", e um dos parâmetros é um salário mínimo anual de 100 mil marcos (em torno de US\$ 50 mil).

$\mathrm{Na}$ verdade, o debate em torno da imigração ganhou maior vulto quando, em 24 de fevereiro de 2000, o chanceler alemão Gerhard Schröeder propôs que as fronteiras do país fossem abertas para especialistas em informática provenientes de países não pertencentes à União Européia.

O secretário-geral do Partido Social-Democrata (SPD) Franz Müntefering salientou, na ocasião, o caráter paliativo da proposta, expressando sua posição de modo que, mais que procurar talentos pelo mundo afora, deve-se estimular a formação profissional dos que já vivem em ter- 
ritório alemão (incluindo-se entre os alemães, os estrangeiros já naturalizados, ou com vistos de residência permanente).

Uma comissão formada pelo Ministério do Interior que agrega representantes dos setores político, sindical e econômico tem-se reunido para estudar as questões implicadas numa reforma das leis sobre a imigração. Esta comissão tem enfrentado questões delicadas para a Alemanha, pois encontram-se realçadas por imperativos como o envelhecimento da população e o atual atrelamento do desenvolvimento econômico ao domínio das novas tecnologias.

Após meses de trabalho, essa comissão recomendou, em seu relatório de julho de 2001, a abertura para concessão de 50 mil "vistos de trabalho" por ano, para imigrantes altamente qualificados, abrangendo cinco setores - inclusive cargos administrativos -, lançando-se efetivamente na concorrência internacional pelas melhores cabeças.

Ainda que cercado por um grande tabu, a idéia de que estrangeiros façam parte do futuro, de longo prazo, da Alemanha parece inevitável. A história da imigração na Alemanha nos remete a diferentes contextos, como o dos anos 60 com os turcos, recebidos como "trabalhadores convidados" (Gastarbeiter) e que terminaram conseguindo licenças de residência e ficando no país.

Estatísticas e análises demográficas recentes da Alemanha apontam que, se o índice atual de natalidade se mantiver, a população alemã, em poucas décadas, sofrerá um expressivo decréscimo.

No entanto, concomitante ao atual empenho do governo alemão em atrair mão-de-obra qualificada de países não pertencentes a União Européia, um relatório publicado em meados de 2001, da Comissão contra o Racismo e a Intolerância do Conselho da Europa, aponta um aumento de $59 \%$ no número de crimes racistas ocorridos na Alemanha no ano de 2000.

Alemães da Construção Civil Emigrando para Países da União Européia - Uma novidade nas migrações internacionais tem sido a contratação de alemães da parte oriental - ex-comunista, onde as taxas de desemprego ultrapassam os $20 \%$ - por países como Holanda, Irlanda, Inglaterra.

Para citar apenas um destes países-destino, temos o caso da Holanda, que nos últimos anos baixou sua taxa de desemprego para números próximos de $2 \%$. A Randstad uma das maiores agências de contratação de mão-de-obra da Holanda - vem participando das atuais feiras de trabalho realizadas em Leipzig e em Chemnitz, disputando trabalhadores de fábricas e do setor de construção. Nestas mesmas feiras, agências irlandesas têm buscado trabalhadores com maior especialização, para trabalhar em centrais telefônicas, enquanto países como a Islândia dispõem de centenas de vagas para a agricultura e setor de construções.

Ainda que sob realidades variadas, o histórico dessas migrações encontra-se balizado pela centralidade do trabalho como motivador desses deslocamentos. Contudo, sob um pragmatismo que impregna as ações dos diversos atores envolvidos nas atuais questões migratórias, ocultam-se as intrincadas situações em que esses estrangeiros deparam-se ao chegar nos países a que se destinam.

São ainda incipientes as ações governamentais de suporte aos estrangeiros "convidados" a trabalhar nesses países com carência de mão-de-obra.

Para os trabalhadores do setor de construção na Holanda oferece-se um salário de cerca de US\$ 1.200 , moradia gratuita - dividida com outros quatro ou cinco trabalhadores - e suas famílias permanecem na Alemanha.

O desemprego na Alemanha encontra-se em cerca de $8 \%$ na parte ocidental e por volta de $18 \%$ na parte oriental.

Os recrutadores estrangeiros que buscam pedreiros e carpinteiros na parte oriental da Alemanha, buscam também soldadores, jardineiros, empacotadores e construtores de rodas de moinhos.

Essas transformações no mundo do trabalho vêm causando entre os alemães particular desconforto. A penúria de mão-de-obra qualificada e a "exportação de braços" para os países vizinhos evidencia a fragilidade de uma autoimagem que se construiu calcada em visões de uma pretensa superioridade alemã.

\section{Inglaterra entre Cérebros e Braços, e seu Estoque de Imigrantes}

O que vem configurando a atuação da Inglaterra em questões de imigração não difere muito dos outros países membros da União Européia. Ações governamentais de estímulo à permanência de "cérebros" em solo britânico e à formação de jovens ${ }^{5}$ nas áreas tecnológicas das universidades do país, bem como o empenho na atração de mãode-obra superqualificada vinda de países estrangeiros rivalizando com os Estados Unidos -, paralelamente ao controle rigoroso da entrada de estrangeiros via portos e 
aeroportos do país, sintetizam a postura do governo inglês diante dos novos fluxos migratórios que caracterizam os anos recentes.

No entanto, o que tem despertado a preocupação das autoridades inglesas é o aumento dos conflitos raciais em diversas localidades da Inglaterra.

Entre os mais violentos desses conflitos, destacam-se aqueles ocorridos entre os meses de maio e julho de 2001, nas cidades de Bradford, Burnley e Oldham, localizadas no norte da Inglaterra. Estas cidades caracterizam-se pela perigosa confluência de elevados índices de desemprego - acima da média nacional de 4,6\% - e alta concentração de moradores de origem estrangeira - no caso, asiáticos (indianos, paquistaneses e bengaleses). (Ressalte-se que a situação descrita a seguir fora registrada antes dos atentados terroristas aos Estados Unidos, o que se crê que tais contextos podem ter ganho novos componentes de tensão.)

Bradford tem uma população de 468 mil habitantes, dos quais $15 \%$ são de origem asiática; A população de Burnley é de 91 mil habitantes com 10\% de imigrantes asiáticos, e Oldham tem 219 mil habitantes, com $11 \%$ de sua população de origem asiática.

Esses imigrantes chegaram à Inglaterra nos anos 60, estimulados pelo governo britânico, para suprir a falta de mão-de-obra no norte do país, cuja indústria têxtil prosperava. Hoje, seus filhos enfrentam a pobreza e a falta de empregos gerados pela decadência dessa indústria no meio dos anos 80. Entre os jovens asiáticos, o índice de desemprego é de $40 \%$. O problema da falta de trabalho também atinge diretamente os jovens da comunidade branca - cerca de $25 \%$ estão sem emprego.

$\mathrm{O}$ isolamento - fruto de equivocadas ações governamentais - e o preconceito que atinge comunidades de imigrantes no norte da Inglaterra, associados ao alto índice de desemprego dessas regiões do país, têm culminado nos enfrentamentos de jovens filhos de imigrantes indianos, paquistaneses e bengaleses e jovens ingleses, brancos.

Manningham, bairro localizado na cidade de Bradford, é quase que exclusivamente habitado por paquistaneses e outros imigrantes asiáticos, onde a língua mais falada é o urdu - língua oficial do Paquistão -, usada em todas as sinalizações do comércio local. Nesse bairro a integração entre imigrantes e britânicos é quase inexistente e as poucas relações são geralmente tensas.

Em entrevista concedida ao jornal Folha de S.Paulo (15/07/2001), o líder da Frente Nacional, Terry Blackham, respondendo à pergunta sobre qual a posição da Frente Nacional diante das comunidades de estrangeiros que vi- vem na Inglaterra, disse: "Queremos que todos os nãobrancos sejam mandados de volta para seus países. Essa gente é responsável por todos os problemas enfrentados pelo Reino Unido atualmente. O povo britânico precisa reagir e se livrar dessa gente, antes que a situação piore ainda mais".

Nas eleições parlamentares de junho de 2001 na Inglaterra, o Partido Nacional Britânico e a Frente Nacional obtiveram cerca de $1 \%$ da votação total; em cidades como Oldham, o inglês Nick Griffin, formado em direito pela Universidade de Cambridge, obteve 16,4\% dos votos dos eleitores de sua cidade.

\section{A Espanha e a Intolerância diante da Crescente Imigração}

A Espanha vem experimentando nos últimos anos um consistente crescimento econômico acompanhado de redução de taxas de desemprego, o que vem lhe conferindo papel de relevo nos debates no interior da União Européia.

O que vem toldando essa prosperidade são os gravíssimos episódios gerados pela retomada das ações terroristas do grupo separatista ETA, voltando a estampar-se na cena pública espanhola. Crescem também os problemas relacionados a imigração ilegal - em particular aquela associada à prostituição - que vem preocupando a Espanha e seus países vizinhos.

Um dos focos de preocupação é Ceuta, um enclave espanhol na costa norte da África e o Estreito de Gibraltar pois, vem adquirindo crescente espaço na rota da imigração ilegal para a Espanha. Por esta região, entram imigrantes procedentes da África subsaariana, de Serra Leoa, Nigéria, Senegal, Mali, Guiné, Gana e também Marrocos. O percurso feito pelos imigrantes, de seus países de origem à fronteira da Espanha, chega a durar até um ano, atravessando desertos e mares. Toda a costa sul da Espanha vem-se mostrando vulnerável à entrada de imigrantes ilegais, tornando-se alvo de pressões dos países membros da União Européia.

Respondendo ao aumento do número de imigrantes que entraram ilegalmente na União Européia - estima-se em 500 mil pessoas, só no ano de 2000 -, a Espanha deteve 15 mil imigrantes ilegais no mesmo ano de 2000 (número quatro vezes superior ao do ano de 1999), dos quais $20 \%$ são procedentes da África subsaariana.

O jornal espanhol El País (27/01/2001) divulgou parte dos dados da pesquisa desenvolvida pelo Centro de Pesquisas Sociológicas (CIS) com base no ano de 2000, em 
que, no tocante a percepção interna do problema da imigração ilegal na Espanha, aponta que, concomitante ao aumento da satisfação da população espanhola com o desempenho econômico do país, cresceu a intolerância do espanhol diante da presença do imigrante em seu país, chegando a $48,6 \%$ dos entrevistados.

A mesma pesquisa revela que $85,5 \%$ dos entrevistados acreditam que o número de imigrantes aumentará nos próximos anos. O relatório desenvolvido pelo CIS, condensando estes e outros dados sobre o assunto, foi encaminhado ao Secretário de Estado para as Relações com as Cortes, Jorge Fernández.

Já os resultados da pesquisa nacional, realizada pelo Instituto da Juventude na Espanha com jovens entre 15 e 29 anos, divulgou em seu Informe Juventude na Espanha 2000 que, perguntados sobre o aumento de imigrantes no país, $30 \%$ dos jovens responderam que a imigração "é prejudicial em nivel racial", e consideram que ela traz "efeitos negativos na moral e nos costumes dos espanhóis".

Imigração Ilegal e Prostituição na Espanha - Pesquisas realizadas por ONGs como a Médicos do Mundo que anualmente produz um relatório que, entre outras estatísticas, apresenta aquelas referentes a imigração e prostituição na Espanha -, divulgadas pelo jornal espanhol $E l$ País (01/12/2000), apontam que $63,2 \%$ das prostitutas na Espanha são estrangeiras (69\% provenientes da África negra, 20,5\% da América Latina, 8,2\% da Europa), fenômeno que vem ganhando contornos mais nítidos desde os meados da década de 90 . Números como estes apresentados pela ONG Médicos do Mundo são partilhados, por exemplo, com a Chefatura Superior de Polícia de Madri, uma vez que a Secretaria de Estado para a Imigração carece de estudos sobre o assunto.

A Espanha vem-se constituindo, nos últimos anos, não só em destino, mas via de passagem de imigrantes para países como: Alemanha, Itália e Holanda, entre outros da União Européia.

Pela predominância das nigerianas entre as imigrantes que trabalham em redes de prostituição em Madri, sabese que entram ilegalmente no país por intermédio de "redes" que atuam na Espanha e que cobram dessas jovens pela trajetória de 3.400 quilômetros e pela transposição de obstáculos que as separam de seus locais de origem e o país-destino, uma importância que chega a US\$ 40 mil, que serão pagos parceladamente, por meio da retenção da maior parte dos ganhos provenientes dos "serviços" dessas jovens, conforme contrato firmado; o que vem sendo tratado pelas autoridades policiais espanholas como "tráfico de escravas sexuais".

\section{Romênia e Turquia - Fronteiras da União Européia?}

Condicionante ao pleito da Romênia para integrar-se à União Européia está a exigência de Bruxelas de um maior controle sobre a fronteira da Romêmia com a Moldávia (ex-integrante da URSS), visando conter a crescente entrada de imigrantes clandestinos provenientes de Bangladesh, Afeganistão, Índia, China, Iraque e Irã, entre outros.

A fronteira da Romênia com a Moldávia, que se estende por 686 quilômetros, passou a ser percebida como a fronteira oriental da União Européia e tornou-se alvo de crescente atenção das autoridades da UE. No entanto, esta fronteira não se encontra equipada para os desafios que se lhe apresentam.

A exemplo do que se passa na extensão de outras almejadas fronteiras, as "redes" que se organizam em solo romeno e em outros pontos da rota de imigração clandestina, desenvolvem ardilosos esquemas, com recursos que muitas vezes superam os destinados pelas autoridades nacionais à vigilância dessas fronteiras.

Autoridades romenas reivindicam apoio financeiro e logístico da União Européia para reforço de suas fronteiras, alegando não dispor de recursos para os investimentos que se fazem necessários, uma vez que enfrentam gravíssimos problemas de migração interna, que agravam-se a cada dia pela falta de recursos para equacioná-los - caso mais notório é o das chamadas "crianças das trevas", um contingente que beira o número de 5 mil crianças, vivendo nos esgotos da capital Bucareste, provenientes de províncias e aldeias rurais do interior do país.

A Turquia também desponta entre as fronteiras que separam os pobres do cobiçado espaço compreendido pela União Européia. O número de imigrantes ilegais capturados na Turquia aumentou de 28.439 em 1997 para 47.518 em 1999 e só nos primeiros seis meses de 2000 já contavam 40.245 capturados, e a maior parte deportada. Estima-se que milhares de outros imigrantes não são capturados.

Em Istambul - como apontou matéria publicada no jornal The New York Times (25/12/2000) -, encontra-se com razoável facilidade passaportes falsos vendidos por preços que variam de US\$250 (iraniano) à US\$ 14.000 (norte-americano com a foto do comprador). Um passaporte do Irã oferece viagens sem necessidade de visto para a Bósnia, donde pode-se encontrar uma "vaga" em cami- 
nhões de carga que passam por Sarajevo e chegam à Áustria. (O fato da crescente prática de falsificação de passaportes, desde os atentados terroristas de 11 de setembro aos Estados Unidos, passou a merecer atenção especial, nas investigações em curso.)

\section{Irlanda, Holanda, Itália - Atração, Repulsão}

A Irlanda que desde a década passada vem sendo uma das economias que mais cresce na Europa, também vem marcando presença na disputa por mão-de-obra estrangeira. Antes, um dos países mais pobres da Europa, a Irlanda agora se tornou um gigantesco centro de serviços - de modo destacado nas telecomunicações - para empresas européias e americanas. Seus emissários enviados às feiras de trabalho que acontecem na Alemanha e outros países da UE, são dos mais exigentes, e a cada dia ampliamse as vagas disponíveis ao trabalhador estrangeiro.

A Holanda também vive um momento de busca por mãode-obra, desde trabalhadores pouco especializados até aqueles altamente qualificados. Os números do desemprego na Holanda, conforme estatísticas do governo, encontram-se em 2,6\% da população ativa, o que eqüivale a aproximadamente 181 mil pessoas; taxa que desde os anos 80 só veio melhorando, até atingir o presente resultado.

Com o problema agora vivido da falta de mão-de-obra na Holanda, empresas e federações sindicais têm desenvolvido as mais criativas campanhas para a contratação de novos funcionários, entre holandeses e estrangeiros.

Já a situação da Itália - que conta com 1,5 milhão de imigrantes legais (2,5\% de sua população total) -, no atual momento das migrações internacionais e da formação dos blocos regionais, centra suas atenções no norte do país, onde a demanda cada vez maior de mão-de-obra estrangeira vem desencadeando reações de protesto entre os italianos quanto a "implantação" de outras culturas em seu território.

É preocupante pelo que tem de sintomático o fato de, em pesquisas de opinião, encontrar-se persistentemente associada à reclamação de insegurança, o aumento do número de imigrantes no país.

Nesse contexto, um dos partidos da coalizão de centrodireita que governa o país - a Liga do Norte - propôs um projeto de lei transformando em delito a "permanência clandestina em território italiano"; a Força Itália do premiê Silvio Berlusconi, é apoiada pela Liga Norte (LN) e a Aliança Nacional (AN), e caracterizam-se na questão da imigração, por posições claramente xenófobas. (Declarações do premiê Silvio Berlusconi, logo após os atentados terro- ristas de 11 de setembro aos Estados Unidos, reforçaram tal percepção, ao declarar ser a civilização ocidental superior às demais.)

Um dos empenhos da Itália em tempos de União Européia tem sido a tentativa de conter e restringir a chamada "unificação familiar" em solo italiano, que faz com que mais e mais imigrantes entrem em seu território (encontro de parentes que ficaram e aqueles que partiram e hoje intentam retornar à Itália, com cônjuges e filhos nascidos no estrangeiro, além de outros familiares). Outra das fontes de preocupação do governo italiano são os imigrantes provenientes dos países do leste europeu.

O ministro italiano das Reformas Institucionais Umberto Bossi - líder da LN -, chegou a propor a construção de um muro de 260 quilômetros de comprimento separando o nordeste da Itália da fronteira com a Eslovênia, visando, assim, impedir a imigração por esta fronteira. Propostas como esta, redigidas por lideranças políticas e autoridades governamentais, são eloqüentes sinais do ânimo das autoridades que conduzem o presente processo de formação dos blocos regionais e do quão obsoletas mostram-se as ferramentais com as quais redesenham o mundo.

\section{NOTAS FINAIS}

Como neste "mapeamento" deixou-se de apresentar o contexto das migrações internacionais entre os países membros do Mercosul, uma vez que se buscou centrar nos principais países-destino de imigração no âmbito das migrações internacionais, e entre os países do $\operatorname{Mercosul}^{6}$ não se encontra nenhum país com este perfil, apresentam-se, a seguir, algumas notas sobre a situação do Brasil no quadro das migrações internacionais.

Em particular ao Brasil, verifica-se nas últimas duas décadas, sensíveis mudanças quanto a posição do país no quadro das migrações internacionais; de tradicional terra de imigração, o país vem figurando entre aqueles que cedem mão-de-obra para o exterior.

O contexto da estagnação econômica brasileira que caracterizou a década de 80 - chamada "década perdida" foi o estopim para a emigração brasileira, que ganhou novo fôlego na entrada da década de 90 , com a abertura econômica e o descrédito em relação as conquistas da redemocratização - leia-se crise do governo Collor.

Dados recentes, na revista Veja (18/07/2001:94), apontam que o número de brasileiros que vivem em países do exterior aproxima-se da cifra de 2 milhões de pessoas, com os cinco principais países-destino e o número destes emi- 
grantes, respectivamente: Estados Unidos (800.000), Paraguai (455.000), Japão (254.000), Alemanha (60.000) e Portugal (52.000). Estes cinco países concentram mais de $80 \%$ dos emigrados brasileiros.

Sendo os Estados Unidos o principal destino também dos imigrantes brasileiros, um dos locais para onde se destinaram um a cada três brasileiros que migraram para este país, foi a região de Boston, no Estado de Massachusetts. Das pesquisas desenvolvidas por Teresa Salles (1995:98-9), verifica-se que: "Essa região tem recebido imigrantes de várias partes do Brasil, mas é, sem dúvida, o fluxo migratório Governador Valadares-Boston aquele que se estabeleceu mais fortemente naquela região dos Estados Unidos. Outra marca importante desse fluxo migratório de brasileiros é que ele é constituído sobretudo de trabalhadores que se integram no chamado mercado de trabalho secundário. [...] Os empregos no mercado de trabalho secundário são aqueles que requerem pequeno ou nenhum treino, estão na mais baixa escala de salários, oferecem pouca ou quase nenhuma oportunidade de mobilidade e são caracterizados pelo rápido turnover."

Quanto a situação dos brasileiros em outras cidades dos Estados Unidos para as quais costumam se destinar, como Nova York, não difere sensivelmente do verificado em Boston. Estes brasileiros, em sua maioria, procedentes dos Estados de São Paulo, Minas Gerais, Rio de Janeiro, Espírito Santo e Goiás, são jovens, classe média e com escolaridade de nível médio.

Os números mais recentes disponíveis apontam que, entre os anos de 1990 e 1997, apenas 44.216 brasileiros receberam o green card.

Com relação ao segundo país em número de brasileiros emigrados - o Paraguai - o histórico dessa migração remonta aos anos 1960-70, e passa por políticas de estímulo ao desenvolvimento da região fronteiriça daquele país e o barateamento de terras naquela região, adquiridas por pequenos e médios agricultores da região sul do Brasil. Nos anos recentes, nota-se novos contornos nesse fluxo, com pessoas sem posses e emprego no Brasil, emigrando para trabalhar nas fazendas dos atuais colonos "brasiguaios".

A presença dos brasileiros nas principais cidades do lado paraguaio da fronteira entre os dois países é marcante, chegando a ser maioria, como na cidade de San Alberto onde, dos 23 mil habitantes, $80 \%$ são descendentes de brasileiros.

Ao mesmo tempo que é exaltado o progresso promovido pelos colonos brasileiros nessas terras, os conflitos com a população nativa agudiza-se misturando componentes econômicos, políticos e raciais. Nessas cidades limítrofes, a fronteira é quase indistinta, configurando-se em zona de comércio recíproco. Prolifera também o contrabando, e ganha espaço o narcotráfico. A vigilância das fronteiras é precária.

Após os atentados terroristas de 11 de setembro sofrido pelos Estados Unidos, essa fronteira passou a ser objeto de preocupação de autoridades nacionais e internacionais, pela facilidade de trânsito entre os três países limítrofes. Cogita-se a presença de membros de redes criminosas, incluindo-se entre estes, grupos terroristas.

Outro grupo de emigrados brasileiros que ganharam visibilidade, é o dos dekassegui - descendentes de japoneses que migraram para o Japão. Atraídos por salários bem superiores aos que poderiam ganhar em solo brasileiro e iludidos por uma frágil afinidade construída por uma ascendência que muitas das vezes não legou-lhes mais que traços fenotípicos e um conjunto de palavras do idioma japonês que, pronunciadas, revelam, sobretudo, a distância deles em relação ao Japão dos dias atuais. Estes imigrantes enfrentam em solo japonês longas jornadas de trabalho, moradias precárias e o preconceito que os condenam à solidão ou aos guetos de brasileiros em igual situação.

Sobre brasileiros em países da Europa Ocidental importantes trabalhos vem sendo desenvolvidos por diferentes pesquisadores brasileiros (Bógus, 1995:111-21).

\section{NOTAS}

1. Sobre os Estados Unidos - principal país-destino de imigração -, dados parciais do Censo norte-americano de 2000 , já divulgados pela grande imprensa, mostram que, dos 30,5 milhões de habitantes do país nascidos no exterior, 13,3 milhões (44\%) chegaram aos Estados Unidos nos anos 90 . No mesmo censo, aponta-se que $38 \%$ da população de Nova York é de não-americanos.

2. Em 28/06/2001, a Suprema Corte dos Estados Unidos determinou que imigrantes não podem permanecer detidos indefinidamente após o cumprimento de sentenças a que tenham sido condenados, por falta de um lugar para serem deportados. A corte decidiu em favor de Kestutis Zadvydas - nascido num campo de refugiados na Europa em 1948 - e Kim Ho Ma - nascido no Camboja em 1977, migrado para os Estados Unidos com 2 anos de idade. Essa decisão afeta cerca de 3 mil imigrantes em situações semelhantes, nas prisões norte-americanas.

3. Destaca-se o caso dos afegãos que vivem nos Estados Unidos e que, desde o atentado terrorista de 11 de setembro aos Estados Unidos, dividem-se entre apoiar ou não um combate ao Taleban. Invocado como um dos pilares da cultura afegã - o "Nanai wati", que os obriga a dar guarida a quem lhes pede, manifestando, assim, o valor da hospitalidade para os afegãos -, constrange-os quanto a entrega do principal suspeito de ser o mentor do atentado, Osama bin Laden, saudita refugiado no Afeganistão. 
4. O presidente do México, Vicente Fox, chegou a manifestar o desejo de que houvesse, entre os países do Nafta, livre circulação de pessoas, como ocorre na União Européia, mas a idéia, na ocasião, contou com pouquíssimo respaldo no Congresso americano.

5. No bojo de um conjunto de medidas, o Ministério da Indústria e do Comércio da Inglaterra anunciou, recentemente, a disposição de subvencionar com US\$ 6 milhões anuais, um número inicial de 50 especialistas em ciências básicas, visando mantê-los ligados aos laboratórios e universidades públicas do país, desenvolvendo tecnologias de ponta e contribuindo na formação de novos talentos, nas classes das universidades britânicas.

6. Ainda é reduzidíssimo o número de estudos de novos fluxos migratórios entre os países do Cone Sul. Registre-se a recente publicação de Canta, América Sem Fronteiras! de autoria de Margherita Bonassi, tratando de imigrantes latino-americanos no Brasil.

\section{REFERÊNCIAS BIBLIOGRÁFICAS}

BÓGUS, L.M.M. "Migrantes brasileiros na Europa Ocidental: uma abordagem preliminar". In: PATARRA, N.L. (org.). Emigração e Imigração Internacionais no Brasil Contemporâneo. $2^{\mathrm{a}}$ ed., Campinas, FNUAP, 1995.

EL PAÍS. Edição eletrônica de 01/12/2000. . Edição eletrônica de 27/01/2001.
FOLHA DE S.PAULO. 25/02/2001, Caderno Mundo, p.A16. . 15/07/2001, Caderno Mundo, p.A17.

IANNI, O. "Globalização e Diversidade". In: PATARRA, N.L. (org.). Migrações internacionais: herança XX, agenda XXI. Campinas, FNUAP, 1996, v.2.

LE MONDE. Edição eletrônica de 09/05/2001.

MÁRMORA, L. Las politicas de migraciones internacionales. Buenos Aires, Alianza Editorial S.A., 1996.

SALLES, T. "O trabalhador brasileiro no contexto das novas migrações internacionais". In: PATARRA, N.L. (org.). Emigração e Imigração Internacionais no Brasil Contemporâneo. $2^{\mathrm{a}}$ ed. Campinas, FNUAP, 1995.

THE NEW YORK TIMES. Edição eletrônica de 25/12/2000.

. Edição eletrônica de 23/05/2001.

Edição eletrônica de 13/07/2001.

Edição eletrônica de 15/07/2001.

USA TODAY. Edição eletrônica de 09/05/2001.

VEJA. Eles fogem da bagunça. São Paulo, n.1.709, 18/07/2001.

Arnaldo Francisco Cardoso: Sociólogo, Professor de Relações Internacionais da UniFMU. 